\title{
Enrolment of Indigents into the National Health Insurance Scheme in Ghana through the Livelihood Empowerment Against Poverty Programme: What are the perceptions of the community?
}

\section{Patricia Akweongo ( $\square$ pakweongo@ug.edu.gh )}

University of Ghana School of Public Health https://orcid.org/0000-0001-6728-3365

\section{Edmund Voetagbe}

University of Ghana School of Public Health

\section{Fabrizio Tediosi}

Swiss Tropical and Public Health Institute: Schweizerisches Tropen- und Public Health-Institut

Dominic Dormenyo Gadeka

University of Ghana School of Public Health

\section{Paola Salari}

University of Basel: Universitat Basel

\section{Moses Aikins}

University of Ghana School of Public Health

\section{Research}

Keywords: National Health Insurance Scheme, Ghana, Livelihood Empowerment Against Poverty, community perception, community-based approach

Posted Date: December 21st, 2020

DOI: https://doi.org/10.21203/rs.3.rs-131070/v1

License: (9) This work is licensed under a Creative Commons Attribution 4.0 International License. Read Full License 


\section{Abstract}

Background: TheLivelihood Empowerment Against Poverty (LEAP) programme in Ghana as part of its beneficiary programme identifies the poor/indigents for exemptions from premium payments into the National Health Insurance Scheme (NHIS). The criteria for identifying the poor by the LEAP into NHIS is yet to be explored.This paper sought to understand community perceptions of enrolling the poor in the NHIS through LEAPin order to inform policy.

Methods: The study adopted a descriptive cross-sectional study design using a qualitative approach. The study was conducted in three geographical regions: Greater Accra, Brong-Ahafo and Northern region representing the three ecological zones of Ghana between October 2017 and February 2018. The study population included community members, health workers, NHIS staff and social welfare officers/social development officers.Eighty-one In-Depth Interviews (IDIs) and 23 Focus Group Discussions (FGDs) across the three regions. Data were analysed thematically and verbatim quotes from participants are used to support the views of participants.

Results: The study shows that participants are aware of the existence of LEAP and its benefits. There is however a general belief that the process of LEAP has been politicized and therefore favours only people who are sympathizers of the ruling government.Participants are also of the view that the process of selecting beneficiaries lacks transparency. As a result, the participants are not satisfied with the entire selection process. However, the study shows the ability of the community in identifying the poor. Furthermore, the study shows varying concepts of poverty and its identification across the three ecological zones or regions. The study also identifies poverty and cost of treatment as reasons in the decision to enrol into the NHIS. However, poor quality of care, out-of-pocket payment, far travel distance to NHIS registration / renewal centre and delays of the process are suggested barriers to low NHIS enrolment by participants.

Conclusion: There is a general perception of politicization and lack of transparency of the selection of the poor into the NHIS through the LEAP in Ghana. Community-based approaches in the selection of the indigent is recommended to safeguard the NHIS-LEAP beneficiary process.

\section{Background}

In the implementation of social health insurance, the need to protect the poor from paying premiums has led to several initiatives on how to identify and target the poor for exemption. The concept of poverty is noted to be complex and multi-dimensional and hence does not apply to only the absence of money but includes food security, access to basic health services, socio-economic status, living conditions and possessions and assets (Morestin et al., 2009). Getting access to health service is among the most difficult aspects of life for the poor. In low- and middle-income countries the most poor often lacked access to health services with health and economic consequences (World Bank 2000). The connection 
between poverty and access to health services can be seen as part of a higher phase, where poverty leads to ill health and ill health retains poverty (Wagstaff, 2000).

The most poor sections of the population are often weakly represented in public policy making. Public policy decisions in fact are often been taken behind closed doors, as technocratic solutions with limited or no consultation, potentially resulting in lack of public ownership, and weak accountability. Nationwide multilateral discourse, with government, employers and workers as well as academics, civil society and others, is fundamental to adopt optimal public policies. Public discourse is required to guarantee social protection systems and a socially responsible retrieval expected at attaining comprehensive development and social justice (ILO Report, 2014)

In a context of widespread poverty, determining who really is poor can be challenging. Several processes have been used to identify the poor including administrative processes, community processes and mixed method approaches. Administrative processes involve a higher authority such as the ministry or government deciding on who they define as poor. Thirteen percent of indicators used to assess poverty are often derived from household surveys (Morestin et al., 2009).

With the introduction of the National Health Insurance Scheme (NHIS), Ghana has been using the means test and, more recently, the eligibility to the Livelihood Empowerment Against Poverty (LEAP) to identify the beneficiaries as poor for exemptions from premium payments. LEAP is a social cash transfer programme, established in 2008 and funds are disbursed bi-monthly to beneficiaries. The programme is funded from general revenues of the Government of Ghana (50\%), donations from the Department for International Development (DFID) and a loan from the World Bank which aims to provide cash and health insurance to extremely poor households across Ghana in order to alleviate short-term poverty and encourage long-term human capital development (Handa et al. 2013).

All LEAP beneficiaries are also entitled to free registration for NHIS. They however must adhere to some conditions such as sending their children to school and avoiding child labour.

Eligibility for LEAP is based on poverty status and having at least one of three demographic conditions: households with orphan or vulnerable children (OVC), elderly poor, or persons with extreme disability unable to work. Initial selection of poor households is done through a community-based process and is verified centrally with a proxy means test. Within the category of extreme poor, the programme further targets households with one or more (a) persons who are over sixty-five years of age, (b) persons living with a severe disability, and (c) caregivers of orphans and vulnerable children. However, since 2016, as result of the new initiative known as LEAP 1000, the programme has also targeted households with a pregnant woman and children below one year of age (NPC, 2014).

Observation of the LEAP approach to identifying the poor and vulnerable does not clearly show an application of the administrative or community-based approaches to identify the poor and does not show how effective this criterion is at identifying the real poor. Hanson (2006) describes six different targeting mechanisms that have been applied in the health sector, including resource allocation formulae, 
contracting NGOs, user fee exemptions, cash transfers, vouchers, and market segmentation strategies. The LEAP applies the means test of cash transfers. However, the approach to identifying the poor, means of verification of the 'real poor' and how much it is able to reduce the leakage of the true poor into the wider premium group needs to be evaluated. Inability to identify the real poor can lead to high health care expenditure with implication for sustainability of the NHIS. Additionally, community perception of this criteria for identifying the poor and enrolling the poor/indigents into the NHIS through LEAP has not been established. This paper sought to understand community perception of using the LEAP programme in enrolling indigents into the NHIS in Ghana. In addition, it explored reasons for low NHIS enrolments and low renewals.

\section{Methods}

\section{Study design and setting}

The study adopted a descriptive cross-sectional study design using community-based qualitative approach to understand community perceptions of enrolling indigents into the NHIS through LEAP. The study was conducted between October 2017 and February 2018 in three geographical regions of Ghana: Greater Accra, Brong-Ahafo and Northern region. These regions represent the three Ghana's ecological zones (southern, middle and northern zones). The regions are characterized by mixed urban and rural populations. The Greater Accra Region is a coastal region with 4.94 million inhabitants and is the region with the lowest poverty incidence in the southern belt with poverty head count of 5.6.\%. Brong-Ahafo region is located within the middle belt with 2.85 million inhabitants and the region with the high poverty incidence in the middle belt with poverty head count of $27.9 \%$ while the Northern Region represents the northern belt with a population of 3.06 million and with the highest poverty incidence in this belt with poverty head count of $50.4 \%$ (GSS, 2019; 2010). These regions were purposively selected because of similarities in their socio-economic and socio-cultural characteristics. Two districts with relatively high enrolment of indigents from the 2015 membership data of the NHIS were purposively selected from each of these regions. These districts also contain all the level of health facilities: Community-Based Health Planning and Services (CHPS), Health centers, Hospitals, Clinics, Laboratories, Chemical and Pharmacy shops. Additionally, the districts have well established District Mutual Health Insurance Scheme offices and the proportion of indigents within these districts ranged from 4-20\%.

\section{Study Population And Data Collection}

The study population included community members, health workers, NHIS staff and social welfare officers/social development officers in the selected districts of the three regions. Majority of the participants were community members comprising of leaders and poor indigenous people. Data were collected using In-Depth Interviews (IDIs) and Focus Group Discussions (FGDs). These qualitative methods were employed because they produce very rich source of data which reveals the world of the participants, their emotions, and thoughts about the world around them (Ofori-Birikorang, 2009). This approach was also to offer the participants an atmosphere that encouraged them to tell their own stories 
regarding the issues of LEAP and NHIS that affect them without interference. It was to provide them the flexibility, which, in turn, allowed the investigator to seek further clarification.

The participants were selected based on a stratified purposive sampling method. This involved the selection of participants across relevant groups dealing with the same phenomenon of which each group was homogenous enough so that cross-group comparisons can be made (Ritchie \& Lewis, 2003). According to Lapan (2004), face-to-face interviews provide perspectives and insights into special knowledge that only participants possess. Generally, information gathered included community definition and identification of the poor in community, registration renewal, use of NHIS for health services and perceptions of enrolling indigents in the NHIS through the LEAP.

In all, 23 FGDs and 81 IDIs were conducted across the three regions. Forty-seven IDIs were conducted among males and 34 among females (Table 1). 16 IDIs were conducted among various categories of health workers including nurses, midwives, physician assistants and health administrators in each of the regions the study was conducted. Then 6 IDIs were held with health care providers, LEAP officers and scheme officers of the NHIS to understand the criteria for enrolling indigents in each region. In addition, 16 IDIs were held with those enrolled as indigents under the NHIS as well as poor identified by the communities that were not enrolled in each region. 8 FGDs were held among the community members: two male groups and two female groups in the two regions and 7 FGDs were held in one to understand the perception of poverty, criteria for identifying the poor, and perceptions of enrolling indigents into the NHIS through the LEAP. Table 1 provides a summary of the background information of the participants in this study. 
Table 1

Background information of participants

\begin{tabular}{|c|c|c|c|c|}
\hline Participants Information & Greater Accra (GAR) & Brong Ahafo (BA) & Northern (NR) & Total \\
\hline \multicolumn{5}{|l|}{ Data collection Strategy } \\
\hline FGDs & 7 & 8 & 8 & 23 \\
\hline IDIs & 14 & 32 & 35 & 81 \\
\hline \multicolumn{5}{|l|}{ FGDs } \\
\hline \multicolumn{5}{|l|}{ Number/Sex } \\
\hline Males & 4 & 4 & 4 & 12 \\
\hline Females & 3 & 4 & 4 & 11 \\
\hline \multicolumn{5}{|c|}{ Number of Participants in FGDs } \\
\hline Males & 38 & 40 & 40 & 118 \\
\hline Females & 25 & 39 & 38 & 102 \\
\hline \multicolumn{5}{|l|}{ IDIs } \\
\hline \multicolumn{5}{|l|}{ Sex } \\
\hline Males & 8 & 16 & 23 & 47 \\
\hline Females & 6 & 16 & 12 & 34 \\
\hline \multicolumn{5}{|l|}{ Type of Participants } \\
\hline Community members & 13 & 21 & 17 & 51 \\
\hline Health workers & 0 & 6 & 10 & 16 \\
\hline NHIS Staff & 1 & 2 & 4 & 7 \\
\hline $\begin{array}{l}\text { Social welfare Officer / } \\
\text { development officer }\end{array}$ & 0 & 3 & 3 & 6 \\
\hline
\end{tabular}

The study objectives and scope were explained and informed consent obtained prior to the interviews. Confidentiality was assured and consent was requested for recording. Manual note-taking was also carried out to compliment the recording and to serve as a backup. Both the recording and the notes were to help ensure accuracy of data and to facilitate analysis. The interviewees were included based on their acceptability, willingness to participate and to provide information for this study. Reflective interview guide which started with general questions and gradually moved to more specific questions was used. Participants were interviewed in local languages and English where applicable. In order to minimize respondent bias and the risk of reactivity, the questions were asked following the cues from participants. 
All interviews and discussions took place where privacy was assured and at the convenience of the participants. Interviews and discussions lasted from 30 minutes to 2 hours.

\section{Data analysis}

Information gathered during the data collection was manually analysed. First, the conversation notes were developed into field note books at the end of each day and recorded interviews were transcribed verbatim in Microsoft word. Verbatim transcription is the word-for-word reproduction of verbal data, where the written words are an exact replication of the audio-recorded words (Poland, 1995). Participant validation was carried out to ensure trustworthiness and this was done by debriefing the analytical results with participants for agreement (Creswell, 2013). This was possible because initial transcription was done immediately after the interview. Some of the transcribed data were translated from a local language into English. The transcript and notes were read several times to get a sense of the entire data. Secondly, the transcript was subjected to a qualitative content analysis to generate common themes emanating from the data: definition and identification of the poor in community, registration renewal, use of NHIS for health services and perceptions of enrolling indigents in the NHIS through the LEAP programme. Third, typical comments by the various categories of participants: community members, health workers, NHIS staff and social welfare officers/social development officers were abridged into meaningful summary statements and further condensed to form themes. Fourth, the authors critically reviewed the transcription and the analysis to discuss the entire results to ensure that the themes and summary statements reflect participants' views. Statements of the respondents were presented as quotes to substantiate the views expressed.

\section{Results}

\section{Identification of the poor for enrolment into the National Health Insurance Scheme}

The qualitative interviews shared light on community perception of poverty and the enrolment processes in the community. There was no consensus on the definition of a poor person in the community. However, majority defined poverty in terms of ability to afford basic necessities of daily living. These activities of daily living included food, clothing, and payment for health care and school fees of children. Therefore, individuals in the community who had challenges meeting these needs in the community were classified as being poor. The participants were generally of the view that there were many poor people in the community. The following quotes illustrate these points:

"Poverty is when you farm and you are not able to get a good yield, feeding your family becomes a problem; you are unable to pay school fees, this is what we term as poverty" (Male, FGD, NR).

"The poor are persons who are not able to feed themselves and their children. They cannot pay the school fees of their children as well as hospital bills when they are sick. We have a lot of poor people in the villages but in Berekum here it may not be common" (female, FGD, BA). 
Both FGD and IDI participants identified orphans, elderly, people who are sick and unable to work and people with disability as poor people in the community across the three study regions. Participants characterized widows as poor because they have no husband to take care of them. In the opinion of participants, widows who have children often find it challenging to cater for their children especially when they are unemployed. The following quotes support these assertions from participants:

"In this community we know each other very well; and we know the less privilege in this community, such as physically challenged, widows/widowers and orphans when such programme come into the community we encourage them to go and register so that they can benefit from such programmes" (Male, $F G D, B A)$.

"The poor in the community are the orphans, people who are sick and cannot work and women whose husband have died living them with children to take care. They suffer a lot as they are not able to feed the children, take care of their fees and the children will always appear in dirty and torn clothes" (Female, FGD, NR).

"We have orphans, people with disability and those who are sick and cannot work are the poor people in this community. They need help because they have nobody to take care of them" (Male, IDI, GAR)

There were little variations in the definition of poor across Brong Ahafo and Northern regions. Table 2 provides a summary of participants' definition and people identified as poor in the community across the three study sites. 
Table 2

Participants' definition and people identified as poor across the three study regions

\begin{tabular}{|c|c|c|}
\hline Region & Definition of Poor & Identification of the Poor \\
\hline Brong Ahafo & $\begin{array}{l}\text { - Inability to feed self and family } \\
\text { - Cannot send children to school and pay } \\
\text { school fees } \\
\text { - Sick person who cannot work or far } \\
\text { - Unable to renew insurance } \\
\text { - Cannot pay Hospital bill } \\
\text { - Widow } \\
\text { - Aged without a helper } \\
\text { - Inability to afford good clothing }\end{array}$ & $\begin{array}{l}\cdot \text { Orphan } \\
\cdot \text { People with disability } \\
\text { - Dressing of their children } \\
\text { - Physical appearance } \\
\cdot \text { Type of house the person lives in }\end{array}$ \\
\hline $\begin{array}{l}\text { Northern } \\
\text { Region }\end{array}$ & $\begin{array}{l}\text { - Inability to feed self and family } \\
\text { - Cannot send children to school and pay } \\
\text { school fees } \\
\text { - Sick person who cannot work or far } \\
\text { - Unable to renew insurance } \\
\text { - Cannot pay Hospital bill } \\
\text { - Widow } \\
\text { - Aged without a helper } \\
\text { - Inability to afford good clothing }\end{array}$ & $\begin{array}{l}\text { - Orphans } \\
\text { - Disability } \\
\text { - Children wearing tattered clothes } \\
\text { - Appearance and dressing } \\
\text { - Live in dejected houses without } \\
\text { light. }\end{array}$ \\
\hline $\begin{array}{l}\text { Greater Accra } \\
\text { Region }\end{array}$ & - Sick person who cannot work & $\begin{array}{l}\text { - Orphans } \\
\text { - People with disability } \\
\text { - Dressing of the person and family } \\
\text { members } \\
\text { - Physical appearance (tattered and } \\
\text { dirty clothes) }\end{array}$ \\
\hline
\end{tabular}

\section{Identifying The Poor In The Community}

In both IDI and FGD, participants were of the view that it was easy to identify poor people in the community. The poor people could be identified through their general appearance, type of house the person lives in, type of food they eat, inability to pay fees of the children and hospital bills. Some participants indicated that poor people often live in houses that have no electricity because they cannot 
afford to pay light bills, they or their children are often seen in tattered clothes and they are often withdrawn from the community. Hence, people who live in the community with the poor such as community leaders could be used to identify the poor.

"Identifying the people in this community is easy. We know them from the place they live, clothes they wear and the way they even talk and carry themselves around. They are often quiet and do not participate in community activities" (Male, IDI, BA).

"It is not easy to identify the poor, you can only identify the poor when the person is sick and can't afford the medical bills, until someone comes to aid of the patient, you will not be able pay for them, again the physically challenge cannot work and cater for themselves, they live on receiving alms and live in houses without light because they cannot afford to pay the bill" (Male, FGD, NR).

\section{Community Structures For Identifying The Poor}

In both IDI and FGD, community members purported to know the people because they live with them and understand their situation. The use of community leaders including religious leaders were strategies that could be used to identify the poor in addition to simply doing a house to house identification. In their view, religious leaders know members of their congregation that are poor. Besides, poor people could be identified by health workers who attend to patients who are sick. This is because poor people are often unable to pay for the health care they receive. Both community members and health workers were of the view that the hospital could be used to recruit the poor. These suggestions are supported by the following quotes:

"Community leaders could be used to identify people. The church leaders know the people who are poor in their church. So if you want to identify poor people in the community, they should be contacted to assist" (Female, IDI, GAR).

"We have leaders in this community so they can be tasked to identify these people who are poor because they know them and after that the government should send someone in the form of a CID (Criminal Investigating Department) officer to confirm that the people selected are really poor, because some people may be left out if you ask just anybody to do the selection. This could lead to selecting those who are not poor rather to benefit from the support" (Male, IDI, GAR).

"The assembly men and women in the sub-districts know their people and they are in contact with them even though we have community health nurses who go for home visits and outreaches they could reach out to them but those will be very few. The assembly man is from the town and stays with them, he is therefore in a better position to identify the poor people. So we could contact the assembly men to help identify the poor and register them for free" (36 years midwife, IDI, BA).

"...the hospital is one of the places you can use to identify the poor because they cannot afford to pay the hospital bill after treatment. They cannot even buy food when they have been admitted in the hospital" (Female, FGD, NR). 
Table 3 presents a summary of community strategies participants identified as means of identifying the poor across the three study sites.

Table 3

Community strategies for identifying poor proposed by respondents

\begin{tabular}{|c|c|}
\hline Region & Community Strategies to Identify the poor \\
\hline \multirow[t]{5}{*}{ Brong Ahafo } & - Use of community leaders (chiefs and assembly members) \\
\hline & - Use of religious leaders \\
\hline & • House to house Identification \\
\hline & - Use of Social Welfare Officers \\
\hline & - Use of Health facilities (attendees who are unable to pay for care they received). \\
\hline \multirow[t]{2}{*}{ Greater Region } & - Community leaders (chiefs and assembly members) \\
\hline & - Use of religious leaders. \\
\hline \multirow[t]{5}{*}{ Northern Region } & - Use community leaders \\
\hline & - Use of religious leaders \\
\hline & - House to house identification \\
\hline & - Use of social welfare officers \\
\hline & - Attendees who are unable to pay for the care they have received. \\
\hline
\end{tabular}

\section{Reasons For Low Nhis Enrolment And Low Renewals}

Both IDI and FGD participants acknowledged the importance of the NHIS in increasing access to health care. Participants cited poverty and cost of treatment as some of the reasons for registering. However, some participants did not renew their membership. Some participants were also of the view that people with NHIS were given poor quality of service when they attended health care facilities or were still made to pay for the services even when they had active cards.

"What I have to say is that the reason why people are not enrolling is that when you use the card all you get as drug is paracetamol, sometimes even paracetamol that cost 1 cedi 50 pesewas (US\$0.20) you will be told that it's not covered" (Male, FGD, GAR).

"When you have the card and go to hospital, you will be told that this drug is not there or is not covered by the insurance. So many of us do not register or renew the card because of that. If they want people to register or renew their card, it should cover all medicines and sickness" (Female, FGD, NR). 
"There is a discrimination between those who have the insurance and those who don't have the insurance. Those with insurance are packed aside and then priority is given to those who have money to pay. The doctors do not even pay attention to you when you go there with a condition. A child can be rushed to the hospital with high temperature but they won't even bother to attend to the child. So if you want better health care and proper medicine you go without the card" (Male, FGD, BA)

Despite this, health workers who participated in this study did not agree that they provided differential services to insured and non-insured clients. All clients go through the normal procedure in the health facility and are provided with client-specific health care.

"When the person comes and is an insured client, she will go through the normal procedure and goes away without any charge except that the person will need some drugs that we don't have at our end and we will write and the person will go and buy it outside. Other than that if the person is having the insurance and we have everything, then the person will go through the process from beginning till he goes away without any further charge. But for the non-insured, they will also go through the normal process but will be billed and will have to pay before taking their drugs then they go" (Midwife, BA)

Another reason for non-renewal was the challenges involved in the process. Apart from the renewal centres located far away from the community, the process is also characterized by delays. To get a card renewed will require spending several hours at registration centres and in some instance one will have to go to renewal centres several times before being served. The following support these points:

"I am registered because with the card you get free treatment at the hospital when you are sick. If you are poor and you don't register then you will struggle to pay hospital bill. So the insurance is good for everybody especially the poor but renewal is the problem, you have to travel far to the centre for renewal. The last time, I have to go there three times before they could renew my card" (Male, IDI, NR).

\section{Livelihood Empowerment Against Poverty (leap) For Enrolling The Poor}

Interviewees were aware of the existence of LEAP in the community and indicated that it was a useful intervention in reducing poverty in the country. The following quotes support these points:

"The LEAP money helps us a lot because I have two children in school and I use some of the money to pay for their fees and use the rest to care for the family. I have used the rest of the money to buy fowl and if I am out of money, I could sell one and use the money for something" (Female, IDI, BA).

"We have LEAP in this community and is very useful. I know people who are benefiting from it and it is helping them a lot" (Female, FGD, NR)

However, there was a general belief that it has been politicized and only people who are sympathizers of the ruling government are selected to benefit from such programme. In a response to a question on knowledge about LEAP in the community, an IDI participant stated the following in the Northern region of Ghana: 
"There is LEAP in this community but it has been politicized. When they came, they only sent it to communities that have party faithful and they are benefiting from it. It was when they called the assemblyman that the LEAP team will be coming to pay beneficiaries in one town that I got to know about the LEAP programme and the beneficiaries here. It angered other community members that they are not benefiting from the LEAP programme but I explained that it will get to their turn" (IDI AS.)

During the FGDs in Brong Ahafo region, participants also generally agreed that LEAP has been politicized and many beneficiaries are actually not poor. They advocated for the use of chiefs to distribute such welfare schemes for the community in future as illustrated:

"Like my brother said if there is such help it should not be passed through politician but rather the chiefs who will get opinion leaders to assist them identify and distribute the money. This will help but as for our politicians they look out for their political interest and select their party members, so it should be through the chiefs who will select opinion leaders to help identity the poor" (Male, FGD).

The selection of beneficiary districts and communities is often based on criteria which has items such as the level of poverty in the community based on the Ghana poverty map, access to health care and schools in the community. The following quotes from participants indicates how districts and communities are selected for LEAP:

"In fact doing the selection exercise here, a team from Accra met with the municipal implementation team and the criteria they considered was for communities that are most vulnerable, then accessibility to health facilities and accessibility of schools and other social amenities and those were the criteria used in selecting the communities" (Social Development Officer, IDI, BA).

People who are above 65 years without any help, orphans, people with disability and pregnant women with children under one year are automatic beneficiaries of LEAP. Selected beneficiaries are verified in the community before disbursements are made to them.

"In fact the categories are the aged who are 65 years and above without any support and the severely disabled without means of livelihood and orphans and vulnerable children, pregnant woman and those with children under 1 year. These are the criteria for selection on to the LEAP" (Social Worker, IDI, BA). "....We collect information from collateral source before we get to the homes to elicit from them whether actually they are poor. When you pay visit to a place and then you ask collateral sources around then you go into the household you see some of the characteristics. And then we try to also look at our criteria and fit it in and see whether it will merit him or her. We don't just pick people often; we have to go through certain criteria. We need to go through certain things to justify that this man when they say he is poor he is poor" (Social Development Officer, NR)

Nonetheless, participants generally were of the view that the process of selection of beneficiaries was not transparent as it is deemed to be politicized. Hence, only people who have political inclination to the 
incumbent government get selected. This process to them creates a situation where many poor people in the community are left out whilst others who in their opinion are not qualified to benefit get selected.

"We were asked to come and write our names and that the government was going to support the poor and needy but when the support came, we the poor and needy were not added to the list. You rather see people who are strong and healthy enjoying the package. I know a woman whose husband had died and no help coming from anyone but she doesn't get the government package. There is community here where the assemblyman is beneficiary of LEAP. She is strong and working" (Female, FGD, BA).

"The process is not transparent at all. In my community they came and took the names and when they came back to distribute the money, some names were dropped from the list. We have people who live in this community who are very poor and yet they were not given anything. But others who are better were rather given the money" (Male, FGD, NR).

"Truly, when the registration for LEAP was on going they told us they were registering old persons and poor people. Two old women in my household registered including some young ladies from other households. But when the date was due for them to come for their monthly monies the names of the two old ladies were omitted, while, the young ladies had theirs" (Male, FGD, GAR).

Some assembly members interviewed also alluded to the fact that the selection criteria are not transparent enough and community leaders are not involved in the process. For example, an assemblyman in the Brong Ahafo Region had this to say in an interview:

"Yes we have some of the LEAP in this community, when it came we heard the information and we gathered the people but the category for selection is not known to any assembly member and even when it's time to pay them no assembly member or committee member is in the known so we don't even know the schedule of payment and the time they come neither do we know how much they are given" (Assemblyman, IDI, BA)

Participants were of the view that involving more community leaders could improve the process of selecting beneficiaries and make the process more transparent. Also, community sensitization on the process and selection criteria could help disabuse the belief about the politicization of the process and enhance transparency.

"The public should know and be informed about the activities and processes. The chief and opinion leaders should know so they could get the whole community members informed. Once the announcement is done, it will make everyone aware of the process and all the people involved can benefit from the process so that it will not be given to just some selected few in the community" (Male, IDI, BA).

"There is need to educate community members about the process of selecting the people and involve the chiefs and opinion leaders. In doing that people will see the process more transparent than what they do now. Just come to write names and return with few names as beneficiaries. That is why people think it is given to only party members" (Male, FGD, NR). 
"We do partner with the social welfare and then enroll the poor onto the scheme. Social welfare has identified these poor people through the LEAP and we are also able to enroll them free of charge into NHIS" (Male NHIS staff, IDI, NR).

".... Yes, the monthly thing [LEAP] there are conditions attached to it. The conditions are that people living within the LEAP catchment households should not allow their children to be trafficked. They shouldn't allow their children to go to Kayayei, children of school going age should be sent to school and then pregnant women should attend ante natal and post-natal care" (Social Development Officer, IDI, NR).

"We get this list from LEAP and also use that to enroll them into NHIS for free. All LEAP beneficiaries also get registered for free" (NHIS worker, IDI, BA).

\section{Discussion}

This paper seeks to understand community perceptions of using the LEAP programme in enrolling indigents into the NHIS in Ghana. The study finding shows that participants are aware of the existence of LEAP and its benefits. The study however, reveals some negative perceptions of enrolling indigents into the NHIS through the LEAP. There was a general belief that it has been politicized and therefore favours only people who are sympathizers of the ruling government. Participants are also of the view that the process of selecting beneficiaries lacks transparency. As a result, communities are not satisfied with the entire selection process. These findings are consistent with a study on the success of interventions targeted at the poor where errors of inclusion and exclusion are often a result of efforts to "vote catch" by politicians and plain rent-seeking (Farrington et al., 2006). An earlier study by Tesliuc 2010 highlighted the advantages and disadvantages of using local actors to select the poor. Whereas it generates accurate information on who to select it may also generate conflict. Our findings confirm earlier studies where despite the improvement in the exemption criteria of NHIS and the general increase in the awareness of LEAP, the LEAP does not adequately resolve the problem of excluding the poor from the scheme (Agbenyo, Galaa, \& Abiiro, 2017; Atulley, 2015; Kotoh \& Van Der Geest, 2016). Additionally, it raises more questions as to who has been exempted and who has not under the NHIS. It is therefore not surprising that an earlier study (Dixon, Luginaah \& Mkandawire, 2014) suggests that about $30 \%$ of the $65 \%$ of the NHIS members who are exempted from paying premiums could indeed afford to contribute. Moreover, the study shows a lack of compliance with the conditions under the LEAP programme. However, this could be because the beneficiaries and potential beneficiaries lack awareness of the sanctions regarding noncompliance.

An earlier study which had similar findings in the area of lack of transparency and political interference, suggested those perceived biases could possibly be as a result of errors that resulted from practical difficulties in ensuring effective targeting within such rural contexts, inaccurate data on household poverty statuses within the informal sectors of rural communities (Agbenyo et al., 2017). Based on the broad coverage of our study: three ecological zones of Ghana, we argue that this assertion could not be entirely true. This is because the criteria for inclusion in the LEAP and therefore being an exempt of the 
NHIS could easily be verified and identified by the community structures should they be involved. For instance, even though the eligibility for LEAP is based on poverty status and having a household member in at least one of three demographic categories: households with orphan or vulnerable children (OVC), elderly poor, or persons with extreme disability unable to work, all these could easily be verified and identified by the community structures who know potential beneficiaries. We therefore believe that the political influence could be the main factor causing the selection bias. Moreover, the participants were of the view that involving more of community leaders could improve the process of selecting beneficiaries and make the process more transparent.

The study shows that there exists no consensus on definition of who the poor is. However, majority defined poverty in terms of ability to afford basic necessities of daily living. They therefore identified people who are unable to feed themselves and family, those who cannot send their children to school and pay their fees, sick person who cannot work, those who cannot work or farm, those who are unable to renew insurance, those who cannot pay hospital bill, aged without a helper, those who cannot afford clothing, orphan, people with disability, people who cannot afford dresses for their children, the physical appearance of others and the type of house the person lives to indicate the state of poverty. This confirms that the concept of poverty is complex and multi-dimensional and does not apply to only the absence of money but includes food security, access to basic health services, socio-economic status, living conditions and possessions and assets as noted in earlier study (Morestin, Grant, \& Ridde, 2009). Moreover, these various concepts of poverty varied across the three ecological zones or regions. This clearly speaks to the fact that poverty is a context-specific phenomenon (Decoster, Hardeman, Horemans, $\&$ Damme, 2008). These findings therefore show that the community has a clear understanding of who the poor is and moreover, the identification of who is poor should be context specific. Additionally, this suggests that the community would be in a better position to identify the core poor under the LEAP or NHIS when given the opportunity and right training on the conditions under these programmes. Moreover, they were of the view that it was easy to identify poor people in the community. This indicates that they will also be in a better position to devise effective guidelines that could be used to identify poor. It has been shown in an earlier study where a critical analysis of various methods of identifying poor households was carried out that the community criteria of classifying the poorest members correlated with mean testing and the proxy mean testing considered as the gold standard (Aryeetey et al., 2010).

Our study further shows that participants acknowledged the importance of the NHIS in increasing access to health care. For instance, the study shows poverty and cost of treatment as factors influencing participants' decision to enroll in the NHIS. However, poor quality of care, out-of-pocket payment, far travel distance to NHIS registration / renewal centre and delays of the process are suggested barriers to low NHIS enrolment by participants. The findings are in agreement with earlier studies (Jehu-Appiah, 2012; Jehu-Appiah, Aryeetey, Agyepong, Spaan, \& Baltussen, 2012; Kotoh, Aryeetey, \& Geest, 2018). For instance, several studies identified systemic factors including lengthy waiting times at registration centres, occasional shortage of registration materials and perceived poor quality of healthcare provider services, provider attitudes and peer pressure as major barriers to enrolment (Atinga, Abiiro \& Kuganablem, 2015; Dror, Hossain, Majumdar, Pérez Koehlmoos, John \& Panda, 2016; Fenny, Asante, Enemark, \& 
Hansen, 2014; Caroline Jehu-Appiah, Aryeetey, Agyepong, Spaan, \& Baltussen, 2012b). However, in recent times (2019), the NHIS has introduced the use of mobile phone renewal method to address some of the challenges of renewal. With the mobile phone method, members can check status of their NHIS policy and renew their membership by dialling a short code $\left({ }^{*} 929 \#\right)$. The service is free and does not require data service or airtime balance. The membership number is required for entry and members need to have sufficient balance in their mobile phone wallet to complete the transaction. Although the study was conducted in three geographical regions representing the three main ecological zones of Ghana (southern, middle and northern sones), there were limitations. It must be noted that as a qualitative study the findings from this study and implementation contest and dynamics are only applicable to other contexts of similar characteristics. Interpretations of the conclusion should therefore be done with care.

\section{Conclusions}

The study reveals negative perception of enrolling indigents in the NHIS through LEAP. There is a general belief that the process has been politicized and therefore favours only people who are sympathizers of the ruling government. Participants are also of the view that the process of selecting beneficiaries lacks transparency. As a result, they are not satisfied with the entire selection process. The implications of these could not only reduce revenue and risk pooling and eventually compound the sustainability challenges facing the scheme but be a major barrier to the achievement of universal health coverage. However, the study shows the ability of the community in identifying the poor. Further the study shows varying concept of poverty and its identification across the three ecological zones or regions. These indicate the relevance and appropriateness of community-based approach in identifying the poor. Moreover, the study shows poverty and cost of treatment as factors influencing participants' decision to enrol in the NHIS. However, poor quality of care, out-of-pocket payment, far travel distance to NHIS registration / renewal centre and delays of the process are suggested barriers to low NHIS enrolment by participants which agrees with earlier studies. There is therefore the need to resolve them to ensure the sustainability of the scheme.

\section{Abbreviations}

CHPS: Community-based Health Planning Services

DFID: Department for International Development

FGD: Focus Group Discussion

IDI: In-Depth Interview

LEAP: Livelihood Empowerment Against Poverty

NGO: Non-Governmental Organization 
NHIS: National Health Insurance Scheme

OVC: Orphan or Vulnerable Children (OVC)

\section{Declarations}

\section{Ethical approval}

The protocol for the study was reviewed and approved (GHS-ERC 01/05/2016) by the Ghana Health Service Ethics Review Committee.

\section{Competing interests}

The authors declare that they have no competing interests

\section{Funding}

The manuscript is part of the research project 'Health systems governance for an inclusive and sustainable social health protection in Ghana and Tanzania' funded by the Swiss Program for Research on Global Issues for Development. This is a joint programme by the Swiss National Science Foundation (SNSF) and the Swiss Agency for Development and Cooperation (SDC). The funder of the study had no role in the study design, data gathering, analysis and interpretation, or in writing of the report. The corresponding author had full access to all the data in the study and had final responsibility for the decision to submit for publication.

\section{Authors' contributions}

The study was designed and conceptualized by PA in collaboration with MA and FT. The manuscript was initiated by PA, MA, EV and DDG. FT and PS read and reviewed the manuscript. Field work for this initiative was organized by PA, EV and MA. Initial data analysis was conducted by PA, PS, MA, and FT.

\section{Acknowledgement}

We wish to acknowledge the National Health Insurance Authority and the Country Advisory Group Members for providing direction on the areas to focus on in this project. The Swiss National Science Foundation (SNSF) provided funding for the implementation of the project. We also thank all our study participants.

\section{References}

Agbenyo, F., Galaa, S. Z., \& Abiiro, G. A. (2017). Challenges of the Targeting Approach to Social Protection: An assessment of the Ghana Livelihood Empowerment against Poverty Programme in the Wa Municipality of Ghana. Ghana Journal of Development Studies, 14(1), 19. https://doi.org/10.4314/gjds.v14i1.2 
Aryeetey, G. C., Jehu-Appiah, C., Spaan, E., D’Exelle, B., Agyepong, I., \& Baltussen, R. (2010). Identification of poor households for premium exemptions in Ghana's National Health Insurance Scheme: Empirical analysis of three strategies. Tropical Medicine and International Health, 15(12), 1544-1552. https://doi.org/10.1111/j.1365-3156.2010.02663.x

Atinga, RA; Abiiro, GA \& Kuganab-lem, R. (2015). Factors influencing the decision to drop out of health insurance enrolment among urban slum dwellers in Ghana. Tropical Med Int Health, 20(312-21).

Atulley, K. A. (2015). an Assessment of the Livelihood Empowerment Against Poverty Programme in the Bongo District, Ghana. Retrieved from http://ir.knust.edu.gh/xmlui/bitstream/handle/123456789/9480/KENNEDY ATINGA ATULLEY.pdf? sequence $=1$

Creswell, J. (2013). Qualitative Inquiry and Research Design. ThousandOaks: Sage Publications.

Dixon, J; Luginaah, I \& Mkandawire, P. (2014). The National Health Insurance Scheme in Ghana's upper west region: a gendered perspective of insurance acquisition in a resource-poor setting. Soc Sci Med, 122(103-12).

Dror, DM; Hossain, SAS; Majumdar, A; Pérez Koehlmoos, TL; John, D \& Panda, P. (2016). What factors affect voluntary uptake of community-based health insurance schemes in low- and middle-income countries? A systematic review and meta-analysis. PLOS ONE, 11(1-31).

Fenny, A. P., Asante, F. A., Enemark, U., \& Hansen, K. S. (2014). Treatment-seeking Behaviour and Social Health Insurance in Africa: the Case of Ghana under the National Health Insurance Scheme. Global Journal of Health Science, 7(1). https://doi.org/10.5539/gjhs.v7n1p296

Farrington, J., Harvey, P., Slater, R., 2006. Cash Transfers in the Context of Pro-Poor Growth. Research Gate.

Ir, P., Decoster, K., Hardeman, W., Horemans, D., \& Damme, W. Van. (2008). An assessment of household eligibility for Health Equity Fund after four years of pre-identification in Oddar Meanchey, Cambodia. Hso\&P, 23(January 2008), 385-407.

Jehu-Appiah, C. (2012). Reaching the poor in Ghana's National Health Insurance Scheme: Equity aspects and strategies to improve enrolment [PhD Thesis]. Nijmegen: Radboud University.

Jehu-Appiah, Caroline, Aryeetey, G., Agyepong, I., Spaan, E., \& Baltussen, R. (2012a). Household perceptions and their implications for enrolment in the National Health Insurance Scheme in Ghana. Health Policy and Planning, 27(3), 222-233. https://doi.org/10.1093/heapol/czr032

Jehu-Appiah, Caroline, Aryeetey, G., Agyepong, I., Spaan, E., \& Baltussen, R. (2012b). Household perceptions and their implications for enrolment in the National Health Insurance Scheme in Ghana. Health Policy and Planning, 27(3), 222-233. https://doi.org/10.1093/heapol/czr032 
Kotoh, A. M., Aryeetey, G. C., \& Geest, S. Van Der. (2018). Factors That Influence Enrolment and Retention in Ghana ' National Health Insurance Scheme. Kerman University of Medical Sciences, 7(5), 443-454. https://doi.org/10.15171/ijhpm.2017.117

Kotoh, A. M., \& Van Der Geest, S. (2016). Why are the poor less covered in Ghana's national health insurance? A critical analysis of policy and practice. International Journal for Equity in Health, 15(1), 111. https://doi.org/10.1186/s12939-016-0320-1

Morestin, F., Grant, P., \& Ridde, V. (2009). Criteria and processes for identifying the poor as beneficiaries of programs in developing countries, (January).

Poland, B. (1995). Transcription quality as an aspect of rigor in qualita-tive research. Qual Inq., 1, 290310.

Tesliuc E.D. world bank (2010) Targeting the poor ib social safety nets programs. SSN Core Course, (December) 